\title{
Tourism Entrepreneurial Prospects in Bardiya, Nepal: Challenges and Way-forwards
}

\author{
Niranjan Devkota \\ Quest International College, Pokhara University, Nepal \\ niranjan@quest.edu.np \\ Saraswati Gautam \\ Quest International College, Pokhara University, Nepal \\ Seeprata Parajuli \\ Quest International College, Pokhara University, Nepal \\ Udbodh Bhandari \\ Quest International College, Pokhara University, Nepal \\ Udaya Raj Paudel \\ Quest International College, Pokhara University, Nepal
}

\section{Article History}

Received: 2 November 2021

Accepted: 29 November 2021

\section{Keywords \\ Local Tourism, Entrepreneurship Development, Local people's perception, Western Nepal}

Corresponding Editor Ramesh Raj Kunwar kunwar.dr@gmail.com

\section{Abstract}

In the present context of Nepal, tourism is a new cultural expression and performance of national formation. Nepal is ready to deliberately utilize in a modern world as a means of creating a sense of identity and solidarity. The country has developed policies that directly influence and continue to shape tourism activities in Nepal. Despite plethora of literature available in Nepalese tourism sector still less has been paid attention on tourism entrepreneurial prospects and not much talked about regional and sectorial tourism prospects including Bardiya District, which is potential destination for national and international tourist for many causes. Thus, this study aims to identify tourism entrepreneurial prospects along with its challenges and potential recommendation for tourism entrepreneurial development in Bardiya District. This study is based on explanatory research design where local residents residing in Thakurbaba Municipality have been interviewed using structured questionnaire. Primary 
data were collected with 290 respondents selected using convenience sampling methods. Result indicates that $40 \%$ of the local people want to participate on tourism activities and want to get involved in accommodation services (31\%), travel guide (26\%), service foods (22\%), transportation sector (18\%), and other services (3\%). It also finds that the major challenges in development of tourism entrepreneurship in Bardiya is lack of efficient management of transportation within the municipality and security of tourists. Hence, more investment on infrastructure will help to promote tourism entrepreneurial prospects in Bardiya.

\section{Introduction}

The gradual maturation of the tourism industry (partly illustrated by the appearance of more conglomerates), the expanding roles of governments, and the increasing awareness of the scope and implications of tourism in academic circles have all added to the need for specialized studies (Leiper, 1979). The issues raised are only those suggested by the author to be of importance to any consideration of the role of tourism in the developing countries, so it can produce the biased results (Jenkins, 1980). Considering Nepal's growing importance as a tourist destination, with its mountain tourism as an important and famous facet, the Ministry of Tourism's celebration of Nepal Mountaineering (Sagarmatha) Week to mark the silver jubilee of Sagarmatha first conquest has becoming the hour of the need (Pradhan, 1979). A number of economists and social scientists argue that tourism can make a significant contribution to the economic development of developing small countries (Andrew, 1997) including Nepal (Devkota et al., 2020a, 2020b). This system does not eradicate the significant work needed to collect final data, including planning, testing and onsite surveys (Tyrrell \& Johnston, 2001).

Increased awareness of the need to examine tourism's cultural effects sparked a symposium on tourism and cultural change (Devkota et al., 2020b) in connection with the American Anthropological Association's annual meetings in San Francisco ( Smith, 1976). Today, tourism is recognized as a major international economic activity (Devkota et al., 2021). Until 1945, the majority of tourism was domestic and focused on a financial elite, but now there are very significant waves of visitors across international boundaries, from all levels. will help for understanding what strategies the government is following to improve mountain tourism and make ongoing efforts to open up walking areas and ranges, more mountain resorts and more new tourist national parks(Pradhan, 1979). Such rapid growth is easily explained by the increase in the real personal disposable income and leisure time and by transportation innovations since 1945 and the research of international tourism interested economists because of the relatively high and sustainable growth rate of tourist arrivals and the economic implications of this for particular countries and regions(Jenkins, 1980). After 1976, the migration of trekkers and mountaineers into Rolwaling in Nepal has gained momentum. 
The Nepalese government had opened the valley again in 1972, after a long closure for political reasons and "Boon or blight" is the emotional mark for the challenge posed by everyone trying to assess the importance of the new phenomenon for the valley's growth (Baumgartner, 1988). If we are to work towards a management target for urban tourism destinations, it becomes necessary to consider the views of local residents towards the growth of tourism, and to look for ways to bring the public into those planning decisions that affect their society (Murphy, 1981; Devkota et al., 2020a). As mentioned by researchers, this research, through contrasting inhabitants of rural and urban world heritage sites, makes a significant theoretical contribution to the urban and rural tourism and understanding literature of people (Rasoolimanesh et al, 2017). Most of the research concentrate on developed countries rather than developing countries and adequate theoretical framework to provide a better understanding of the views of people is needed (Sinclair-Maragh \& Gursoy, 2016). Sustainable and efficient production of tourist destinations is strongly related to the ability of Destination Management Organization (DMO) to manage destinations and the DMO has been described as the player in control of strategic planning, management and resource organization (Wallet al., 2009). Some of the studies are aimed to promoting tourism in developing countries (Hasselblatt, 1973).

From the above viewpoint, it seems fitting to make an effort to determine the condition of the conventional valley economy at the time of the opening of the gate of this closed world to foreign visitors (Baumgartner, 1988). In present, the situation of tourism continues to play a major role in the economic development of Asian and Pacific countries (Andrew, 1997; Devkota et al., 2021). Murphy (1981) argues that there has been a comparative study of three different types of destination area, seeking community reactions to the industry and ways in which such information may guide future strategies. Weiermair's (2000) study has provided a detailed cultural framework to describe and forecast the actions and judgments of quality of visitors. Further, Baumgartner (1988) argues that his study can hardly be representative for an environment in which ethnical and cultural diversity is the most common quality. Moreover, Nepal (2008) contends that records on actual energy use in rural regions are difficult to obtain. Again, Witt et al. (1994) have asserted that more accurate forecasting can be done by predicting that international tourism demand does not improve relative to the corresponding time than by creating more complex forecasts. Furthermore, Zurick (1992) argues that touristic movement produces a unique tourism space structure that in turn contributes to Nepal's formation of regional developments such as hill town gateways, tourism destinations in the hinterland, and multi-use parks. Regarding the heterogeneity of destination, while we used a prior knowledge to describe heterogeneity through the creation of two data sets, there may be additional heterogeneity within each data set (Rasoolimanesh et al., 2017). 
In the present context of Nepal, we consider tourism as new cultural expression and performance of nation formation (Devkota et al., 2020a, 2020b, 2021). Nepal is ready to deliberately utilize tourism in a modern world as a means of creating a sense of identity and solidarity. We have developed policies that directly influence and continue to shape tourism activities. Nepal is using tourism heavily as a means of promoting the economy diplomacy of the nation through creating a new 'brand' to attract tourists and the country may aim to highlight its particular character and uniqueness and to represent itself in a way that flatters and reinforce national identity (Devkota et al., 2021).

The current research literature on factors affecting entrepreneurial success has focused primarily on manufacturing firms and only on service industries in a secondary manner and almost no attention has been paid to the tourism industry. Very limited research was conducted in Nepal in respect of the tourism entrepreneurial prospects, and it can also be seen from the literature review above that only the limited variables are taken into account for that kind of study. Most importantly it can be seen that there is no research conducted in Bardiya district which include the perception of local people on tourism entrepreneurial prospects and its potentiality. Therefore, this study seeks to explore tourism entrepreneurial prospects in Bardiya, Nepal. The organization of the study is as follows: second section covers the research methods of the study; third section includes research method; and fourth section

\section{Literature review}

The gradual maturation of the tourist industry (partly illustrated by the appearance of more conglomerates), the expanding roles of governments, and the increasing awareness of the scope and implications of tourism in academic circles have all added to the need (and content) for specialized studies Leiper (1979) and It helps to define the tourism, tourist and the tourist industry (Leiper, 1979). The issue raised are only those suggested by the author to be of importance to any consideration of the role of tourism in the developing countries so it can produce the biased resu (Jenkins, 1980). Considering Nepal's growing importance as a tourist destination, with its mountain tourism as an important and famous facet, the Ministry of Tourism's celebration of Nepal Mountaineering (Sagarmatha) Week to mark the silver jubilee of Sagarmatha first conquest is becoming the hour of need (Pradhan, 1979). A number of economists and social scientists argue that tourism can make a significant contribution to the economic development of developing small island countries (Andrew, 1997). This system does not eradicate the significant work needed to collect final data, including planning, testing and on-site surveys (Tyrrell \& Johnston, 2001).

Increased awareness of the need to examine tourism's cultural effects sparked a symposium on tourism and cultural change in connection with the American Anthropological Association's annual meetings in San Francisco (V. L. Smith, 1976). 
Today, tourism is recognized as a major international economic activity. Until 1945, the majority of tourism was domestic and focused on a financial elite, but now there are very significant waves of visitors across international boundaries, from all levels. will help for Understanding what strategies the government is following to improve mountain tourism and make ongoing efforts to open up m: walking areas and ranges, more mountain resorts and more new tourist national parks (Pradhan, 1979). Such rapid growth is easily explained by the increase in real personal disposable income and leisure time and by transportation innovations since 1945 and the research of international tourism interested economists because of the relatively high and sustainable growth rate of tourist arrivals and the economic implications of this for particular countries and regions (Jenkins, 1980). After 1976, the migration of trekkers and mountaineers into Rolwaling has gained momentum. The Nepalese government had opened the valley again in 1972, after a long closure for political reasons and "Boon or blight" is the emotional mark for the challenge posed by everyone trying to assess the importance of the new phenomenon for the valley's growth (Baumgartner, 1988). If we are to work towards a management target for urban tourism destinations, it becomes necessary to consider the views of local residents towards the growth of tourism, and to look for ways to bring the public into those planning decisions that affect their society (Murphy, 1981).This research, through contrasting inhabitants of rural and urban world heritage sites, makes a significant theoretical contribution to the urban and rural tourism and understanding literature of people (Rasoolimanesh, Ringle, Jaafar, \& Ramayah, 2017). Most of the research concentrate on developed countries rather than developing countries and the lack of adequate theoretical framework to provide a better understanding of the views of people is needed (Sinclair-Maragh \& Gursoy, 2016). Sustainable and efficient production of tourist destinations is strongly related to the DMOs ' ability to manage destinations and the DMO has been described as the player in control of strategic planning, management and resource organization (Wall, Willis, \& Roman, 2009).

The study is aimed to Promoting tourism in developing countries (Hasselblatt, 1973).From the viewpoint above, it seems fitting to make an effort to determine the condition of the conventional valley economy at the time of the opening of the gate of this closed world to foreign visitors (Baumgartner, 1988). In present the situation tourism continues to play a major role in the economic development of Asian and Pacific countries (Andrew, 1997). The paper presents a comparative study of three different types of destination area, seeking community reactions to the industry and ways in which such information may guide future strategies (Murphy, 1981). This study provides a detailed cultural framework to describe and forecast the actions and judgments of quality of visitors (Weiermair, 2000). This study Hardly be representative for an environment in which ethnical and cultural diversity is the 
most common quality (Baumgartner, 1988). As the predicting time period rises so do the likelihood of systemic shifts that can affect the future (Witt, Witt, \& Wilson, 1994). Records on actual energy use in rural regions are difficult to obtain, therefore this research is based on the assumption of daily consumption by the lodge owners (Nepal, 2008) From this study we can learn that more accurate forecasting can be done by predicting that international tourism demand does not improve relative to the corresponding time than by creating more complex forecasts(Witt et al., 1994). This movement produces a unique tourism space structure that in turn contributes to Nepal's formation of regional developments such as hill town gateways, tourism destinations in the hinterland, and multi-use parks (Zurick, 1992). This paper analyzes energy consumption patterns in tourist lodges in Nepal's Annapurna region (Nepal, 2008).It is intended to create certain significant and realistic consequences for the agencies responsible for managing the world heritage sites of rural Lenggong and urban George city (Rasoolimanesh et al., 2017).

While we used a prior knowledge to describe heterogeneity through the creation of two data sets, there may be additional heterogeneity within each data set (Rasoolimanesh et al., 2017). Within the context of tourism growth, specific metaphors were used to operationalize such definitions as the ways in which they were frequently referred to in the literature but the question of authority as it applies to the mindset of citizens was not discussed in this report (Sinclair-Maragh \& Gursoy, 2016). Stanford Research Library Tool actually only understands the English language and this caused a problem where only English comments were collected and analyzed through sentiment analysis but They examined just one travel information platform and only one city, Paris, which is difficult to generalize and This research takes datadriven and exploratory method by examining large volumes of the tourist reports (Kim, Park, Yun, \& Yun, 2017).

Stakeholder theory talks about the participation of stakeholders in tourism initiatives have a very important role to play or say they have a huge potential to influence either positively or negatively. If the stakeholder play their role positively by addressing core issue of their communities they can lead toward sustainable tourism development. Similarly place theory explains mental, psychological, cultural and ethical relationships between person and place. Place is the space in which human experience has provided meaning. Sense of place refers to a collection of individual or group identities and attachments to a location. Tourist destinations are a place, a sense of place is a tourist experience. Therefore, the place theory for tourism research is reasonable and necessary. The another theory called social exchange theory explain the importance assigned to the elements of the exchange influence the way in which residents of a destination view tourism and determine the level of acceptance of tourism by the community. 
Similarly, ecology theory talks about its application in tourism's planning process because it view tourism as a part of communities ecosystem and it deals mainly interacting with current dynamic living relationships, an attempt must be made to understand them and, for tourism, this includes a focus on the ecological community setting. Another theory pull and push theory deals with factors that influence people's choices of their holiday destination because there would be no travel industry without a tourist motivation to travel and it to describe tourist conduct and motives for travel. The idea of pull and push factors has been widely accepted. The result of motivation are closely examined with respect to the need for travel. The family life cycle (FLC) theory is used to explain the patterns of tourist behavior in tourism sector. Doxy irridex model which is the causation theory of visitor's resident irritant states that tourism has the negative impact i.e. an increase in the number of tourist and a more developed tourism industry at the destination results in irritation in the host community.

According to plog's model destinations are rising and failing popularity over the period of time and typically this is uses to explain what kinds of individuals, based on their psychographic features, and would choose the styles of destinations. When constructing the model of travel behavior Plog used a general population random sample. In addition to understanding the complexities of passengers, Plog analyzes the root triggers of growing and declining popularity of travel destinations. Similarly Community support Model is based on the social exchange theory which states that the creation of tourism is not carried out in isolation, but takes place in unique contexts, each with its own peculiar features and support for residents is a crucial element in the development and implementation of sustainable policies in these specific places and also Tourist planers should be concerned with the vision and expectations of residents towards tourist projects. Similarly tourism development support model which shows particular relevance to exploring resident attitudes toward tourism in developing countries because it encompasses the role of factors prevalent in developing countries such as international intervention of investment and public policy decisions (imperialist impact), the trust of citizens in government and political institutions, and the issue of identity, which is a critical factor in most developing countries.

The framework has potential applications in several areas of tourist industry management, and the approach seems particularly relevant as a guide for planning and assessing governmental policies in some areas of tourism. A particular government can use the framework to recognize the relationships of its geographical constituency in the tourism system (Leiper, 1979). The tourism development program requires a conscious, coordinated, gradual and systematic study to determine how tourism can best serve the national interest and yet project a country's image as a finest destination 
and Tourism can make a substantial contribution to the cultural, social and economic life of a nation, its undesirable effects also cannot be discounted (Pradhan, 1979). Tourism is a phenomenon which must be tackled on an international level and to get a grip on it, industrial and developing countries must closely cooperate (Hasselblatt, 1973). Tourism's influence is typically greater on the host rather than on the tourist community.

The native can never fully turn himself into the metropolitan citizen (represented by many visitors) nor completely transform his climate. The atmosphere created by and for the tourists is also true for the natives, setting up new meaning orientations of " keeping up with the tourist (Bhandari, 2010). Tourism is seen as a "necessary evil in most developing countries and Only active and positive involvement of government can save the industry from that criticism (Jenkins, 1980). The rapid transition and destruction that we can create within populations that are accustomed to such conditions may potentially rob us of the opportunity to learn from them an important lesson such as how to manage access and use finite renewable resources in a dwindling planet (Baumgartner, 1988). The roles of design and group effects reflect the value of physical and economic impact.

In some cases, York and Torquay need to strengthen their community relations, while Windsor needs to consider major revisions to the policy if it is to build a more positive attitude towards the sector (Murphy, 1981). Tourism operations can be seen as a dynamic network of interrelated facilities embodying a multitude of aspects of service quality (Weiermair, 2000). A decoupling would be possible if the visitor season could be extended or visitors were more dispersed within the area and their lives were totally dependent on tourism without a viable alternative (Akis, Peristianis, \& Warner, 1996). Several factors influence the international tourism market, including exchange rate volatility, global inflationary trends, political / environmental incidents, and shifts in holiday habits (Witt et al., 1994). The settlement of tourism-related land disputes and the introduction of new resource laws in the adventure destinations for both local residents and visitors are important criteria for the long-term success of Nepal's natural and cultural heritage.

The settlement of tourism-related land disputes and the introduction of new resource laws in the adventure destinations for both local residents and visitors are important criteria for the long-term success of Nepal's natural and cultural heritage and also By expanding the spatial centers of tourism to the de-eloping global boundaries and serving as a medium for social and economic contact between developed and developing countries, ad-venture tourism shifts sustainable development issues to the existence of some of the most isolated places in the world (Zurick, 1992). Energy caused by tourism at rural attractions, exacerbates the problem of conserving natural resources at local level and presents a long-term threat to the global climate and also 
there is a high level of dependence on fuel wood and kerosene, and hence the risk of using these resources (Nepal, 2008).

There is a positive relationship between perceived value of tourism development, satisfaction with material life domain, non-material life domain, overall quality of life, and support for further tourism development and also the importance of growth of tourism is a significant precedent for fulfillment of the non-material and material existence environment of the people (Woo, Kim, \& Uysal, 2015). The economic background of people often provides important details, as those who work directly in tourism are worried with unfair resource distribution (Sinclair-Maragh \& Gursoy, 2016).

Baumgartner (1988) noted In Sherpa-community of Rolwaling valley in NorthEastern Nepal that Tourism in harsh mountain valleys of the Himalaya still provides an attractive contrast to our life in affluent societies. Andrew (1997) determines In Maldives that the possibilities for expanding international tourism in the Maldives are limited by the restricted availability of suitable sites for tourist development. Murphy (1981) Suggested in Windsor, Torquay and York that the three tourist centers can indeed be differentiated on the basis of their community attitudes toward tourism development and the stepwise procedure makes it possible to identify the relative importance of individual variables in this differentiation process. Woodside \& Lysonsk (1989) noted in new Zealand that Experience via previous visits to a travel destination was not associated significantly with subjects' categorizing destinations in their consideration set. Akis et al. (1996) suggested in Cyprus that the benefits of tourism outweigh the costs. Witt et al. (1994) noted in France, Germany, United Kingdom, and United States that International tourism demand is influenced by many factors, including exchange rate fluctuations, relative inflationary movements, political/environmental events, and changes in holiday patterns. Zurick (1992) suggested in Nepal that Nepal's adventure tourism also supports the positive development of national parks by raising awareness of the need for environmental creation and the money to support it financially.

Tyrrell \& Johnston (2001) determine in Newport that the total direct sales effect on the area arising from the Folk Festival was significant, but was not equal to the sum of all expenses incurred by those tourists and festival-related participants. Nepal, (2008) noted in Annapurna Region of Nepal that Trekking and mountaineering activities have boosted the innovation and diffusion of renewal energy and energy efficient technologies. Rasoolimanesh et al.(2017) suggested in George Town \& Lenggong valley, Malaysia that the effects of residents' perceptions and participation on support for tourism development differ. Kim et al. (2017) in Paris mentioned that travelers seem to feel positive about their experiences associated with "restaurants", "night life", and "things to do in Paris". 
The framework provides governments with a value-free approach to tourism policy. It is not structured from the perspective of any one (Leiper, 1979). We can make a meaningful contribution to maintain Nepal's superb beauty and splendor (Pradhan, 1979). The development of tourism cannot be stopped, but it must be guided into controllable channels (Hasselblatt, 1973). Moral and practical enigma concerning values or definitions, to guide the cultural change commonly created by tourism between what the anthropologists applied can and ought to do (Bhandari, 2010).Tourism has become a fact of life for a growing number of valleys in the Himalayas and planning policies for such areas need to take this aspect into account when drawing up plans and executing rural uplift schemes (Baumgartner, 1988). None of the tourist centers examined were in the ideal position to be directly linked to both discriminating roles and their relative position provides an opportunity for the three centers to check the suspected interrelations (Murphy, 1981). A simple and useful description of traveler awareness, preference, and choice of competing destinations may be the model of traveler destination choice and the model builds upon multiple proposals and research findings from cognitive and behavioral psychology, marketing, and travel and tourism (Woodside \& Lysonski, 1989). For the same reasons of cultural difference, tourism businesses that need intercultural skills and know-how on management (Weiermair, 2000).

A critical assessment of potential tourism ambitions in Cyprus would be ideal, before the citizens ' negative attitudes demand a policy change (Akis et al., 1996). International tourism demand forecasts generated by different techniques are generally more accurate in the near future, up to one year ahead, than in the more distant future, over one year and up to two years ahead (Witt et al., 1994). The research of adventure travel in Nepal reveals how this type of international tourism expands the cycle of world development into the peripheral nation's frontier regions (Zurick, 1992). Tourism is known as a resource-intensive sector, and must be responsible to sustainability at both local and global levels (Nepal, 2008).

Resident's support for further growth of tourism is partly affected by perceptions of the perceived value of tourism creation in both non-material and material spheres of existence. Changes in these aspects of life in effect lead to changes in satisfaction with life (Woo et al., 2015). The creation of tourism is basically a difference of business planning, and the primary concern is to define and meet customer / tourist needs (Moscardo, 2011). Policymaking on tourism should be closely monitored, especially on an inter-country basis (Jenkins, 1980). Profit from tourism needs to be re-channeled, at least partially, into infrastructure industries relevant to fundamental needs (Baumgartner, 1988). Study found All the centers (Windsor, Torquay and York) require some improvement in community attitude (Murphy, 1981). 
The knowledge and choice of demographics regarding competitive destinations should be regarded as a wise investment in evaluating marketing success and coordinating marketing behavior (Woodside \& Lysonski, 1989). Use a culture system that can be scaled based on its distance or similarity to the cultural norms that exist in the nation receiving tourism (Weiermair, 2000). The desire to prolong the season may well contribute to a more important assessment of tourism's benefits (Akis et al., 1996).The differences in accuracy rankings obtained for forecasts of international tourist flows using annual data as compared to forecasts of domestic tourist flows using seasonal data are indeed due to the international versus domestic dimension and not to the annual versus seasonal nature of the data (Witt et al., 1994).Tourism managers and planners will consider the multidimensional ideals of citizens in order to enhance their happiness with particular areas of life (material / non-material life; culture, health / safety, and emotional life) through the growth of tourism (Woo et al., 2015).Giving local groups the power to create and offer their own social representations of tourism itself is a necessary prerequisite for more inclusive approaches to tourism governance (Moscardo, 2011). Well-managed homes tend to be a suitable alternative commodity, promoting tourism that embraces the country's remoteness and its nature, traditionalism and mysticism (Acharya \& Halpenny, 2013).

More scientific and theoretical work into tourism and its impacts on developing countries is urgently needed (Jenkins, 1980). It's not certain that the Maldives maximized their tourism profits (e.g., local employment). The issue involves more investigation (Andrew, 1997). This existing body of research does not spans various disciplines and covers different branches of tourism and/or tourism activities which should be covered (Weiermair, 2000). Future researcher should focus on eco- and alternative tourism (Akis et al., 1996).Future research lines should be directed towards accurate and appropriate picture measurement scales for rural cultural destinations (Royo-Vela, 2009). In future research, research should try to consider residents' characteristics in order to get better Life satisfaction and support for tourism development (Woo et al., 2015).

For better results future researcher should examine communities that are involved and others that are not involved in tourism development (Lee, 2013). Future research will tackle the critical issue of uncovering heterogeneity which is not observed (Rasoolimanesh et al., 2017). Future studies may resolve this by exploring how to understand and address the concerns of people, especially those who are underrepresented and exploited (Sinclair-Maragh \& Gursoy, 2016). As we all know all the studies on tourism are mostly destination specific, further improvisation of scales can be considered (Mathew \& Sreejesh, 2017). Data analyzes which support a diverse set of languages from different regions are needed in future research to have a better result (Kim et al., 2017). 


\section{Research method}

\section{Study area, population and sampling}

Bardiya district of Nepal is chosen for the study area. Nepal has 77 districts, and $\mathrm{t}$, Thakurbaba municipality of Bardiya district which is situated in province 5 was taken for the study area of this research. The geographic coordinates of Thakurbaba municipality are: latitudes $28^{\circ} 18^{\prime}$ and $59.5^{\prime \prime} \mathrm{N}$ and longitudes. $81^{\circ} 23^{\prime} 13.91^{\prime \prime}$ E. Total population of the municipality is 68012 and the total area of the municipality is 226.09 square kilometers ( $87.29 \mathrm{sq} \mathrm{mi}$ ) and the municipality is divided into total 11 wards. This study was conducted in particular municipality because it has huge potentialities of tourism that could surely impact the tourism entrepreneurs and entrepreneurship in this area. Local residents residing in Thakurbaba Municipality are the population of the study. 290 respondents have been selected using convenience sampling method. After the preparation of the questionnaire, $5 \%$ of the total sample size determination was taken as pre- test.

\section{Figure 1: Study area}

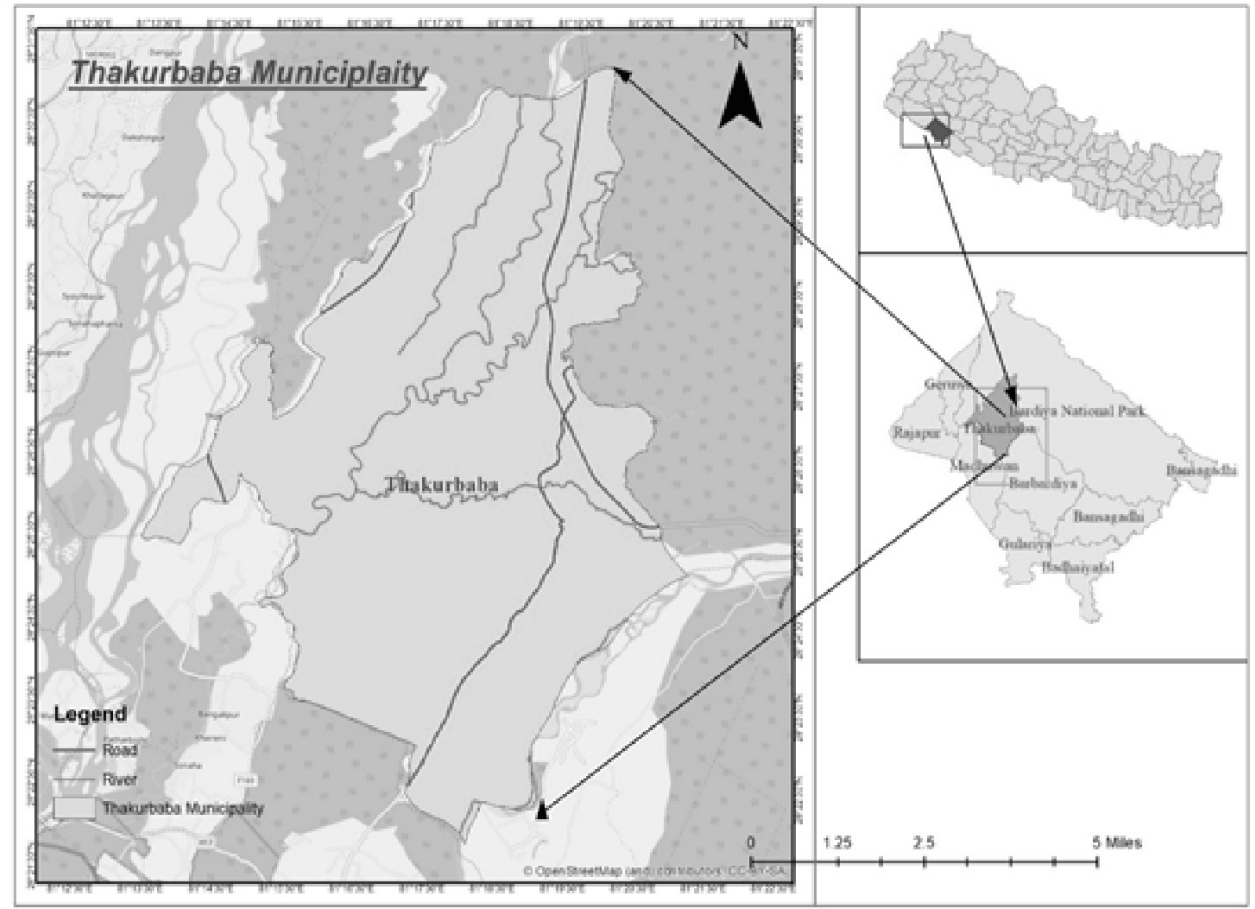




\section{Research instrument and data collection}

In this study, the questionnaire and expert opinions were used. For this purpose, we took the opinions of several experts so as to be clear in issues that came across our project. As mentioned earlier, the data collection is based on structured questionnaire where the participants have provided their responses on the basis of their preferences and assumptions. The questionnaire was in the form of 5- point Likert scale, subjective question and multiple-choice questions. However, the questionnaire was maintained using Kobo toolbox. After the preparation of the questionnaire, $5 \%$ of the total sample size determination was taken as pre- test. The data analysis includes the identification of present status of tourism in Bardiya, identification of the determinants of tourism entrepreneurial development, and identification of challenges in tourism entrepreneurial development and also potentiality of tourism entrepreneurship development in Bardiya.

\section{Result and discussion}

\section{Status of tourism industry in Bardiya}

The Bardiya National Park is one of the most intact protected areas in Tarai and houses of, along with countless other mammals and reptiles, the endangered Royal Bengali tiger and the famed one-horned Nepalese rhinoceros. The Park in Bardiya district is bordered by the Karnali River, to the west, by the Churia River, to the north by the Babai River...

\section{Figure 2: Number of tourist visitors to Bardiya National Park and}

\section{Conservation Area}

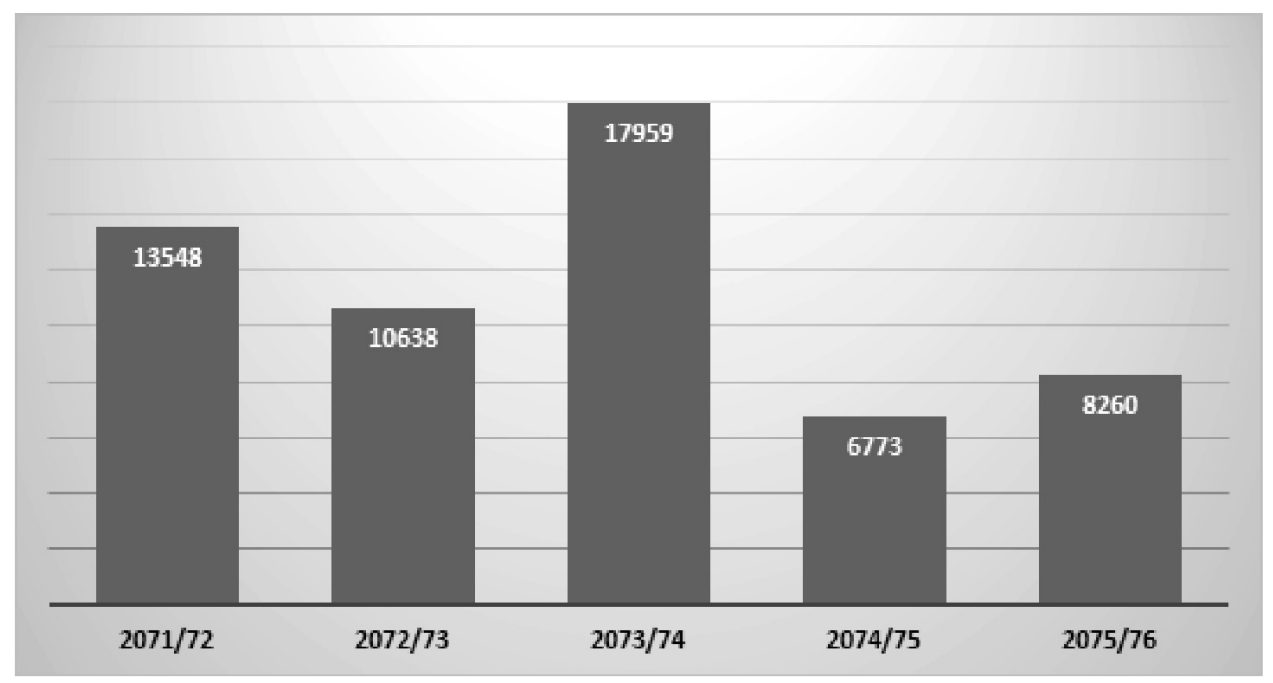

Source : Statistics (2019) 
Figure 2 shows the number of tourist visitors to Bardiya National Park and conservation area. Here, we can see that in fiscal year 2071/72 13548 tourist visited the national park. Similarly, in fiscal year 2072/73 10638 tourist visited the national park. But, in fiscal year 2073/74 the no of tourist has been increased to 17959 and in 2074/75 this number decreases to 6773. In fiscal year 2075/ 76, 8260 tourist visited the Bardiya national park.

Figure 3: Number of tourists visited at national park and conservation area by month

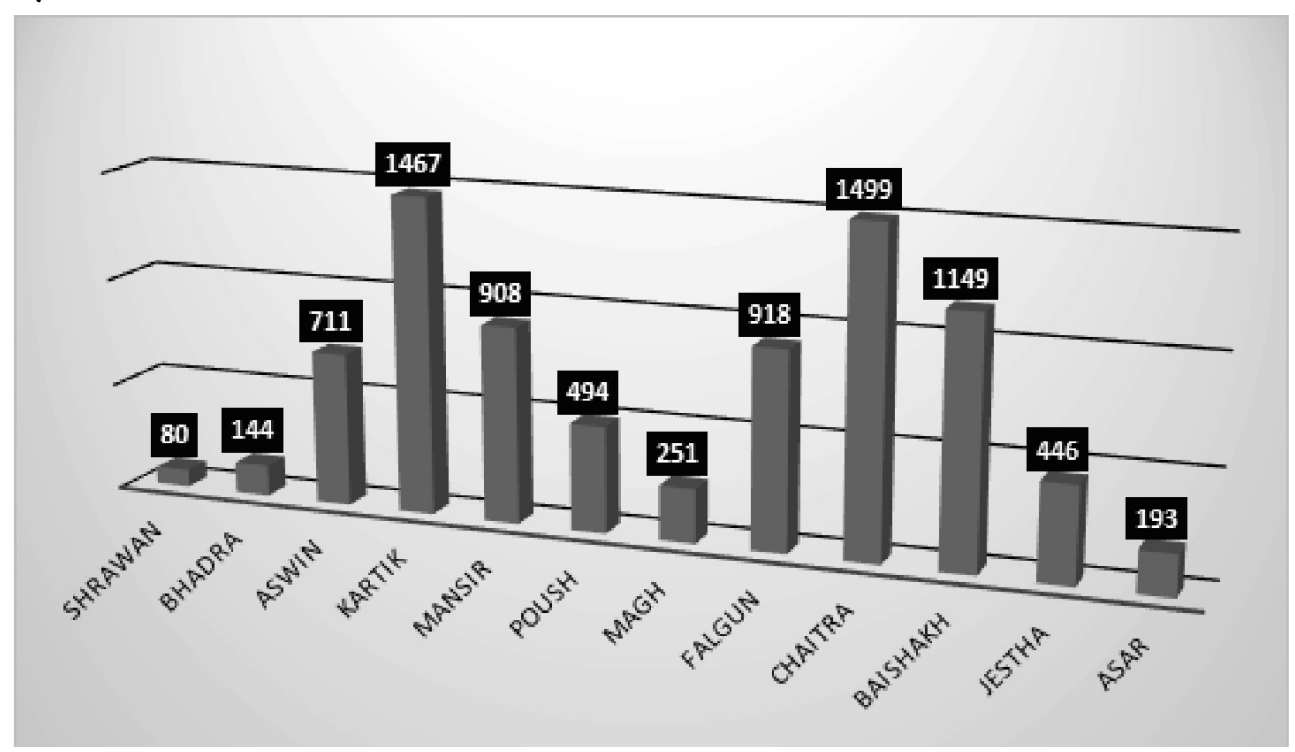

Source: Statistics (2019)

Figure 3 shows the number of tourists visited Bardiya national park and conservation area by month in the fiscal year 2075/76. In the month of shrawan, 80 tourists visited the national park area. Similarly, 144, 711, 1467,908,494,251,918 and 1499 tourist visited national park on the month Bhadra, Aswin, Kartik, Mansir, Poush, Magh, Falgun, and Chaitra respectively. Similarly, on Baisakha, Jestha and Asar $1149,446,193$ tourists visited the national park respectively. In this regard, Zurick (1992) suggested in Nepal that Nepal's adventure tourism also supports the positive development of national parks by raising awareness of the need for environmental creation and the money to support it financially.

\section{Socio- demographic analysis}

Socio-demographic statistics basically deals with personal characteristics of population expressed statistically such as age, sex, marital status, education level, working experience (Bergman \& Strulovici, 1970). Our study shows that there are 
altogether $79 \%$ male and $21 \%$ female out of total respondents. Majority of respondents that is $52 \%$ are in the age group between $25-35$ followed by $36-45(35 \%)$. In terms of their marital status, $67 \%$ of respondents are married followed by $30 \%$ who are single, $1 \%$ have been divorced, widowed and others. In terms of education, people are educated since only $11 \%$ of respondents opined they are educated below SEE level.

Table 1: Socio-demographic characteristics of respondents

\begin{tabular}{|c|c|c|}
\hline & Number & Percentage \\
\hline \multicolumn{3}{|l|}{ Gender } \\
\hline Male & 229 & 79 \\
\hline Female & 61 & 21 \\
\hline \multicolumn{3}{|l|}{ Age } \\
\hline Up to 25 & 15 & 5 \\
\hline 26 to 35 & 150 & 52 \\
\hline 36 to 45 & 103 & 35 \\
\hline Above 45 & 22 & 8 \\
\hline \multicolumn{3}{|l|}{ Marital status } \\
\hline Married & 193 & 67 \\
\hline Single & 86 & 30 \\
\hline Divorced & 4 & 1 \\
\hline Widow & 4 & 1 \\
\hline Others & 3 & 1 \\
\hline \multicolumn{3}{|l|}{ Education } \\
\hline None & 4 & 1 \\
\hline Primary & 28 & 10 \\
\hline Lower secondary & 20 & 7 \\
\hline Upto SEE & 51 & 18 \\
\hline Plus two & 78 & 27 \\
\hline Bachelor & 82 & 28 \\
\hline Masters & 27 & 9 \\
\hline
\end{tabular}




\begin{tabular}{|l|c|c|}
\hline Profession & & \\
\hline Hotel & 48 & 17 \\
Resturant / café & 47 & 16 \\
Souvenir shops & 14 & 5 \\
Tour operators & 16 & 6 \\
Travel agencies & 36 & 12 \\
Others & 129 & 44 \\
\hline Work experience & 81 & 28 \\
\hline Below 5 years & 146 & 50 \\
$10-5$ years & 24 & 8 \\
$11-15$ years & 23 & 8 \\
$16-20$ years & 16 & 6 \\
Above 20 years & & \\
\hline
\end{tabular}

As a profession, 44\% have been performing their duties other than tourism related business followed by travel agency business (12\%), tour operators (6\%), and conducting souvenir shops (5\%). While, $16 \%$ of them have owned restaurant and cafe and $17 \%$ of them are in hotel business. It also finds that out of 290 , only $32 \%$ of respondents who are in hotel business sector while $36 \%$ are in agricultural sector and $23 \%$ are in government sector and $9 \%$ of them have gone for foreign employment. Our study finds only $22 \%$ of them are involved in tourism sector. It indicates that despite having possibility of tourism in that area, people chose not to engage in it and earn a good living. $78 \%$ of respondents have their family members around 1-5 engaged in the tourism business followed by $20 \%$ who have around 6-10 family members involved. Similarly, 78\% of respondents have work experience of 5-10 years in tourism business whereas $6 \%$ have more than 15 years of work experience in this field. In this regards, Sapkota (2019) argues that tourism thrives on teamwork which requires synergy between basically three major components: the government, private investors and business people, and the community.

Table 2: Other Economic Characteristics of the Respondents

\begin{tabular}{|l|c|c|}
\hline Duration of staying in village & & \\
\hline Under 5 years & 48 & 17 \\
6-10 years & 74 & 25 \\
Above & 168 & 58 \\
\hline
\end{tabular}




\begin{tabular}{|l|c|c|}
\hline Family occupation & & \\
\hline Agriculture & 105 & 36 \\
Foreign & 26 & 9 \\
Government & 66 & 23 \\
Hotel/business & 93 & 32 \\
\hline No of family members & & \\
\hline Below 10 & 263 & 91 \\
10 to 15 & 17 & 6 \\
16 to 20 & 10 & 3 \\
\hline Involvement in tourism business & 226 & 78 \\
\hline Yes & 64 & 22 \\
\hline No & & \\
\hline No of family member involved in tourism business & 50 & 78 \\
\hline 1 to 5 & 13 & 20 \\
6 to 10 & 1 & 2 \\
more than 10 & 50 & 68 \\
\hline Work experience in Tourism business & 4 & 6 \\
\hline less than 5 years & & \\
5 -10 years & & \\
11 -15 years & & \\
More than 15 years & & \\
\hline
\end{tabular}

\section{Prospects of tourism entrepreneurship development}

To find out the potentiality of tourism entrepreneurship $t$ in Bardiya district, questionnaires are asked to the local people to seek their opinion about participation, benefits, possibility, and ability from which researchers will try to recommend potentiality of tourism entrepreneurship development in Bardiya. 40\% of the local people wants to participate on tourism activities where $60 \%$ of the local people don't want to participate in any tourism activities, which shows that the income of the people not only depend on the tourism activities but also, they are involved in other filed like agriculture, government employees, etc. Further, $31 \%$ percept of people wants to provide accommodation service, $26 \%$ of people want to provide service as travel guide, $22 \%$ of people want to serve people by serving food, $18 \%$ of people want to give service of transportation and vehicle and remaining 3\% of people want to give other services. 
$25 \%$ of people think that they have local knowledge and they can easily run the tourism business in their village, $23 \%$ of people think that they have experience of working locally from which they can take the advantage, $20 \%$ of people think that they have support of local government so that they can run the business easily and $17 \%$ of people think that they can use family labor which can create advantage to them. Similarly, $13 \%$ people think that they can start tourism business in less cost in comparison of other business and $2 \%$ people have mentioned that there are other advantage too. However, there are several disadvantages. The major disadvantage in participating in tourism according to the local people is language limitation and lack of professional training which occupy the $18 \%$ among the total. Similarly, $16 \%$ people think that lack of skill and knowledge on tourism is another major disadvantage. Likewise, another $16 \%$ of the people think that restriction on communication and international exchange is another disadvantage. Similarly, $9 \%$ of the total people think that lack of experience working in tourism is another disadvantage and $8 \%$ people think that there is other disadvantage too.

Among the total respondents, when asked about if there is benefit of tourism entrepreneurship to your community or not $54 \%$ of total respondents agreed that there is benefit in tourism where $46 \%$ of the respondents disagree about the benefit to their community. Among the total respondents, when asked about the possible benefit of tourism to your community, $30 \%$ of the respondents answered that tourism help to develop local economy, $38 \%$ of the respondents answered that tourism helps to create employment opportunities. Similarly, 29\% respondents answered that tourism helps to increase family income and remaining 3\% of respondents think there are other benefits too. In this sense, Solvoll et al. (2015) argue that Tourism entrepreneurship is an innovation and transformation in the tourism sector in order to take advantage of opportunities related to the demand for experience-based products.

Among the total respondents $20 \%$ of respondents think that if tourism industry grows in the village it can help to create large no of jobs and income for local. Similarly, $16 \%$ respondents think that if tourism industry grows in the village, it can help to boost international culture exchange. $15 \%$ of respondents agreed that tourism preserve and develop local culture. It gives the sense with the earlier paper Paudel et al. (2021) which mentioned that cultural diversity plays vital role for the development of local tourism. 14\% of respondents agreed that tourism help to develop local economy and it enhances the quality of local business as well. $12 \%$ of the respondents believe that tourism help to increase the knowledge of local residents and $8 \%$ of the respondents agreed that tourism help to raise the awareness of local residents. Remaining $1 \%$ of the respondents think that there are other possibilities too.

Among the total respondents, when asked whether their village has the ability to develop tourism, $57 \%$ of the respondents believe that their village has the ability to 
develop tourism but the remaining $43 \%$ of respondents disagreed. The respondents who believe the village has the ability to develop tourism are asked why they think that their village has the ability and $41 \%$ of the respondents answered that there is much potential but not yet exploited. $33 \%$ of the respondents answered that there is much potential but it is under exploited. Similarly, $11 \%$ of the respondents believe that there is lot of potential and is being well exploited and also there is little potential for tourism development. $4 \%$ of the respondents believe that there is other reason too behind their answer.

The respondents were asked how can community participate in local tourism as it is vital for the development of the tourism. $37 \%$ of the respondents agreed that they have to participate moderately (so far so good) and voluntarily as well. 15\% of the respondents believe that they have to participate compulsory and $11 \%$ of respondents believe that there is no need to participate community to develop tourism industry.

\section{Challenge of tourism entrepreneurship development}

There are numerous challenges on the way toward the development of tourism entrepreneurship. To find out the real challenges of tourism entrepreneurship development researcher asked two questions to the respondent. Those question are presented below. In the first question respondents were asked is there any challenge or not. $76 \%$ of the total respondents agreed that there is challenge and rest of the respondents i.e., $42 \%$ of respondents believe that there is no challenge. Respondents have responded as they have been facing many challenges on the way towards the development of tourism entrepreneurship. Result shows that $27 \%$ of the respondents believe that lack of efficient management of transportation within the municipality is a major challenge to develop tourism. $15 \%$ of the respondents agreed that the security of the tourist is one of the major challenges towards tourism development. Likewise, insufficient investment and lack of skilled manpower are also another major challenge which occupy the $15 \%$ of the total respondents' view. Another $17 \%$ of respondents think that to make tourist stay long is another major challenge. Similarly, $9 \%$ of respondents believe that to meet the expectation of the tourist is also a major challenge while developing the tourism entrepreneurship in Bardiya.

\section{Managerial solution for betterment of tourism entrepreneurship development}

Regarding, managerial solution, $10 \%$ of the total respondents believe that there is no need to give suggestion but rest of the $90 \%$ of respondents have given the suggestions for the betterment of the tourism entrepreneurship development within the district. In response to the question asked to the $90 \%$ of the respondents they believe that they can give some suggestions which can be the managerial solution. In the part of the managerial solution which was the open-ended question various responses were gathered. $31 \%$ of the respondents mentioned that more investment 
should be done to improve quality. The second most strategical implication suggested was that government should play role in facilitating and supporting local tourism which is mentioned by the $19 \%$ of the total respondents. $15 \%$ of the respondents mentioned that more hotels with more facility should be opened. $12 \%$ of the respondents mentioned that professional training should be given. $11 \%$ of the people mentioned that local people should actively participate in tourism activities. $8 \%$ of the respondents believe that tourism related organization should focus on promoting local culture. $4 \%$ of the respondents believe that youth empowerment programs in tourism sector should be conducted.

\section{Conclusion}

The study conducted aimed at identifying and analyzing the Local people's perception on tourism entrepreneurship in Bardiya district. This study included 290 participants where about $79 \%$ are male and $21 \%$ are female. Most of the respondents were identified between 25 to 35 years of age group followed by the age group of 36 to 45 . The socio-demographic outcome further indicated that the majority have completed their studies up to the bachelor's level and there were few respondents having education level above masters. Furthermore, that $78 \%$ of the respondents are not involved in tourism business which shows that despite having possibility of tourism in that area, people chose not to engage in it and earn a good living. Similarly, $22 \%$ of them are involved in tourism sector. People who thought they could affect policy decisions and tourism companies had little influence on decision making attitudes were more favorable than residents who were less dominant. Community power is a vital mechanism for supporting the industry's sustainability growth. Enabling urban people to take decisions may be an important strategy to shape and promote their perceptions. Based on the analysis and conclusion, some recommendation are (i) Local people should get chance to participate on the planning and decision-making regarding tourism development (ii) Government should make flexible policies to encourage the local people on tourism activities (iii) Security system must be strong for the safety of the tourist (iv) Local government should focus on giving training to youth for betterment of tourism, and (v) People should more focused on creating experience rather than selling tourism product.

This research is focused on the local people's perception on tourism entrepreneurship prospects in Bardiya district. This research analyzes and result to assist tourism planners, tourism related organization, policy makers regarding hoe they initiate the tourism entrepreneurship development. This work may be useful for more researchers in the same area of study and for prospective students, who would develop their understanding of Tourism sector and its development. In Nepal there have been limited studies on these emerging tourism entrepreneurship prospects. Since this study only covers descriptive analysis, study with inferential analysis may 
help to replicate the results of this study and to identify additional potential factors that affect the support for tourism development. Future studies should analyze factors that affect in real life development process. The future researcher could take more sample size to make the research more appropriate. Thus, potential researchers can further analyze variables and add or remove variables according to the study.

\section{References}

Acharya, B. P., \& Halpenny, E. A. (2013). Homestays as an alternative tourism product for sustainable community development: A case study of women-managed tourism product in rural nepal. Tourism Planning and Development, 10(4), 367387.

Akis, S., Peristianis, N., \& Warner, J. (1996). Residents' attitudes to tourism development: The case of Cyprus. Tourism Management, 17(7), 481-494.

Andrew, B. P. (1997). Tourism and the economic development of maldives. Annals of Tourism Research, 24(3), 721-735. https://doi.org/10.1016/s0160-7383(97)00026-1

Baumgartner, R. (1988). Tourism and socio-economic change: The case of the rolwaling valley in Eastern Nepal. Tourism Recreation Research, 13(1), 17-26. https://doi.org/10.1080/02508281.1988.11014520

Bergman, R., \& Strulovici, N. (1970). Socio-demographic characteristics of Israeli student nurses. International Journal of Nursing Studies, 7(2), 67-79. https://doi. org/10.1016/0020-7489(70)90025-8

Bhandari, K. (2010). Tourism in Nepal: Post-monarchy challenges. Journal of Tourism and Cultural Change, 8(1-2), 69-83.

Devkota, N., Paudel, U.R., \& Bhandari, U. (2020a). Tourism entrepreneurs' expectation from the provincial government in touristic city-Pokhara, Nepal. Journal of Hospitality and Tourism Insights, 3(3), 329-351.

Devkota, N., Paudel, U. R., \& Bhandari, U. (2020b). Does westernization influence the business culture of a touristic city?. Economics \& Sociology, 13(4), 154-172.

Devkota, N., Paudel, U. R., \& Bhandari, U. (2021). Conveying Impetus for Fostering Tourism and Hospitality Entrepreneurship in Touristic Destination: Lessons Learnt from Pokhara, Nepal. The Gaze: Journal of Tourism and Hospitality, 12(1), 88-111.

Hasselblatt, W. B. (1973). Tourism promotion in developing countries. Intereconomics, 8(8), 241-244. https://doi.org/10.1007/BF02927698

Jenkins, C. L. (1980). Tourism policies in developing countries: a critique. International Journal of Tourism Management, 1(1), 22-29. https://doi.org/10.1016/01432516(80)90018-3 
Kim, K., Park, O. joung, Yun, S., \& Yun, H. (2017). What makes tourists feel negatively about tourism destinations? Application of hybrid text mining methodology to smart destination management. Technological Forecasting and Social Change, 123, 362-369. https://doi.org/10.1016/j.techfore.2017.01.001

Lee, T. H. (2013). Influence analysis of community resident support for sustainable tourism development. Tourism Management, 34, 37-46.

Leiper, N. (1979). The framework of tourism. Towards a definition of tourism, tourist, and the tourist industry. Annals of Tourism Research, 6(4), 390-407. https://doi. org/10.1016/0160-7383(79)90003-3

Mathew, P. V., \& Sreejesh, S. (2017). Impact of responsible tourism on destination sustainability and quality of life of community in tourism destinations. Journal of Hospitality and Tourism Management, 31, 83-89.

Moscardo, G. (2011). Exploring social representations of tourism planning: Issues for governance. Journal of Sustainable Tourism, 19(4-5), 423-436.

Murphy, P. E. (1981). Community attitudes to tourism. A comparative analysis. International Journal of Tourism Management, 2(3), 189-195. https:/doi. org/10.1016/0143-2516(81)90005-0

Nepal, S. K. (2008). Tourism-induced rural energy consumption in the Annapurna region of Nepal. Tourism Management, 29(1), 89-100.

Paudel, U. R., Puri, S., Parajuli, S., Devkota, N., \& Bhandari, U. (2021). Measuring Cultural Diversity Impact in Hospitality Industry Leadership: Managerial Communication Perspective from Five Star Hotels in Kathmandu Valley, Nepal. Journal of Tourism \& Adventure, 4(1), 75-88.

Pradhan, G. B. N. (1979). Mountain tourism in Nepal. Tourism Recreation Research, 4(1), 37-39. https://doi.org/10.1080/02508281.1979.11014974

Rasoolimanesh, S. M., Ringle, C. M., Jaafar, M., \& Ramayah, T. (2017). Urban vs. rural destinations: Residents' perceptions, community participation and support for tourism development. Tourism Management, 60, 147-158.

Royo-Vela, M. (2009). Rural-cultural excursion conceptualization: A local tourism marketing management model based on tourist destination image measurement. Tourism Management, 30(3), 419-428.

Sapkota, L. (2019). Tourism thrives on Teamwork. Kathamndu Post, p. 7.

Sinclair-Maragh, G., \& Gursoy, D. (2016). A Conceptual Model of Residents' Support for Tourism Development in Developing Countries. Tourism Planning and Development, 13(1), 1-22. https://doi.org/10.1080/21568316.2015.1047531 
Smith, V. L. (1976). Tourism and culture change. A symposium. Annals of Tourism Research, 3(3), 122-126.

Tyrrell, T. J., \& Johnston, R. J. (2001). A framework for assessing direct economic impacts of tourist events: Distinguishing origins, destinations, and causes of expenditures. Journal of Travel Research, 40(1), 94-100. https://doi. org/10.1177/004728750104000112

Smith, V. L. (1976). Tourism and culture change. A symposium. Annals of Tourism Research, 3(3), 122-126.

Wall, R., Willis, K. G., \& Roman, V. (2009). Management of Archaeological and Heritage Attractions : a Case Study of. Tourism, 505(January), 487-505. https:// doi.org/10.1002/jtr

Weiermair, K. (2000). Tourists' perceptions towards and satisfaction with service quality in the cross-cultural service encounter: Implications for hospitality and tourism management. Managing Service Quality: An International Journal, 10(6), 397-409. https://doi.org/10.1108/09604520010351220

Witt, C. A., Witt, S. F., \& Wilson, N. (1994). Forecasting international to u $r$ is $t$ flows. 21(3), 612-628.

Woo, E., Kim, H., \& Uysal, M. (2015). Life satisfaction and support for tourism development. Annals of Tourism Research, 50, 84-97.

Woodside, A. G., \& Lysonski, S. (1989). A general model of traveler destination choice. Journal of Travel Research, 27(4), 8-14.

Zurick, D. N. (1992). Adventure Travel and Sustainable Tourism in the Peripheral Economy of Nepal: Discovery Service for Universitat Oberta de Catalunya. Annals of the Association of American Geographers, 82(4), 608-628. 